\title{
Estudo de desempenho de um sistema híbrido fotovoltaico/térmico
}

\author{
Performance study of a hybrid photovoltaic/thermal system \\ Estudio de rendimento de um sistema híbrido fotovoltaico/térmico
}

\author{
Ramon Rudá Brito Medeiros \\ ORCID: https://orcid.org/0000-0002-0923-1644 \\ Universidade Federal do Ceará, Brasil \\ E-mail: ramon.ruda@ufc.br \\ Arthur Vila Nova Albuquerque Lima \\ ORCID: https://orcid.org/0000-0003-3363-8409 \\ Universidade Federal do Ceará, Brasil \\ E-mail: arthur.vna.lima@hotmail.com \\ Gutembergy Ferreira Diniz \\ ORCID: https://orcid.org/0000-0003-1773-7933 \\ Universidade Federal de Uberlândia, Brasil \\ E-mail: gutembergy_ferreira@hotmail.com \\ Vinicius Mafra Melo \\ ORCID: https://orcid.org/0000-0001-9587-6205 \\ Universidade Federal da Paraíba, Brasil \\ E-mail:vmafram@hotmail.com \\ Luiz Guilherme Meira de Souza \\ ORCID: https://orcid.org/0000-0003-1234-1729 \\ Universidade Federal do Rio Grande do Norte, Brasil \\ E-mail: lguilherme@dem.ufrn.br \\ Kelly Cristiane Gomes da Silva \\ ORCID: https://orcid.org/0000-0002-0255-8740 \\ Universidade Federal da Paraíba, Brasil \\ E-mail: gomes@cear.ufpb.br
}

\begin{abstract}
Resumo
Este trabalho apresenta um estudo de desempenho de um sistema híbrido fotovoltaico/térmico (PVT), comparando-o com um sistema fotovoltaico tradicional (PV). Foram analisadas a potência elétrica e térmica, a eficiência e a energia produzida pelos sistemas. O módulo fotovoltaico (PV) utilizado foi o MSX 77 da marca SOLAREX, composto por células solares policristalinas, cuja potência de pico é de 77 Watts. O sistema PVT analisado foi do tipo PVT-líquido, composto pelo mesmo módulo PV e um coletor solar plano do tipo placa, a alimentação de água do coletor foi do tipo forçada por gravidade. Para determinar as curvas características do módulo PV e por consequência a potência elétrica máxima gerada, foi desenvolvido um banco de carga formado por resistores de potência. A potência térmica foi quantificada aferindo a vazão da água que alimentava o coletor e a diferença de temperatura da água de entrada e saída. Com as potências e a radiação solar incidente sobre os sistemas, foram determinadas as eficiências. O sistema PVT proporcionou a redução da temperatura do módulo $\mathrm{PV}$, aumentando a eficiência de geração elétrica, proporcionando um aumento na ordem dos $6,9 \%$ na energia elétrica média diária. O sistema PVT além de proporcionar um aumento de energia elétrica, ainda fornece energia térmica com uma eficiência superior à elétrica. A água aquecida pode ser utilizada para alimentar sistemas de aquecimento de água para banho, contribuindo para redução do consumo de energia elétrica de uma residência.
\end{abstract}

Palavras-chave: Fotovoltaico; Sistema híbrido; PV; PVT.

\begin{abstract}
This work presents a performance study of a hybrid photovoltaic/thermal system (PVT), comparing it with a traditional photovoltaic system (PV). The electrical and thermal power, efficiency and energy produced by the systems were analyzed. The photovoltaic module (PV) used was the MSX 77 of the SOLAREX brand, composed of polycrystalline solar cells, whose peak power is 77 Watts. The PVT system analyzed was of the type PVT-liquid, composed of the same PV module and a flat solar collector of the plate type, the water supply of the collector was of the type forced by gravity. In order to determine the characteristic curves of the PV module and, consequently, the maximum electrical power generated, a load bank formed by power resistors was developed. The thermal power was quantified by measuring the water flow that fed the collector and the temperature difference of the inlet and outlet water. With the powers and solar radiation incident on the systems, the efficiencies were determined. The PVT system reduced the temperature of the PV module, increasing the efficiency of electrical generation, providing an increase in the order of $6.9 \%$ in the average daily electrical energy. The PVT system, in addition to providing an increase in electrical energy, also provides thermal
\end{abstract}


energy with a higher efficiency than electrical. The heated water can be used to feed water heating systems for bathing, helping to reduce the consumption of electricity in a home.

Keywords: Photovoltaic; Hybrid system; PV; PVT.

\section{Resumen}

Este trabajo presenta un estudio de desempeño de un sistema híbrido fotovoltaico/térmico (PVT), comparándolo con un sistema fotovoltaico tradicional (PV). Se analizó la potencia eléctrica y térmica, la eficiencia y la energía producida por los sistemas. El módulo fotovoltaico (PV) utilizado fue el MSX 77 de la marca SOLAREX, compuesto por células solares policristalinas, cuya potencia máxima es de 77 Watts. El sistema PVT analizado fue del tipo PVT-líquido, compuesto por el mismo módulo fotovoltaico y un colector solar plano del tipo placa, el suministro de agua del colector fue del tipo forzado por gravedad. Para determinar las curvas características del módulo fotovoltaico y, en consecuencia, la potencia eléctrica máxima generada, se desarrolló un banco de carga formado por resistencias de potencia. La potencia térmica se cuantificó midiendo el caudal de agua que alimentaba el colector y la diferencia de temperatura del agua de entrada y salida. Con los potencias y la radiación solar incidente en los sistemas, se determinaron las eficiencias. El sistema PVT redujo la temperatura del módulo fotovoltaico, aumentando la eficiencia de la generación eléctrica, proporcionando un aumento del orden del 6,9\% en la energía eléctrica diaria promedio. El sistema PVT, además de proporcionar un aumento de la energía eléctrica, también proporciona energía térmica con una eficiencia superior a la eléctrica. El agua calentada se puede utilizar para alimentar sistemas de calentamiento de agua para el baño, lo que ayuda a reducir el consumo de electricidad en un hogar.

Palabras clave: Fotovoltaica; Sistema híbrido; PV; PVT.

\section{Introdução}

Água potável e a energia são dois requisitos básicos para a sobrevivência da vida na terra (Singh et al., 2016; Al-Nimr \& Qananba, 2018). A energia solar é a energia primária da cadeia energética da vida, que garante a sustentabilidade do nosso planeta, sendo, portanto, responsável pela garantia da existência humana (Sahota \& Tiwari, 2017). Sem energia solar não haveria vida, pois, a cadeia alimentar estaria totalmente comprometida.

Além de ser a energia primária, a energia solar é também a de maior magnitude. Seu potencial energético é algumas vezes maior que o consumo mundial de energia. Essa fonte de energia está largamente disponível em todas as regiões do planeta, além de ser inesgotável e limpa, podendo ser utilizada por pessoas de qualquer nível social, cultural e intelectual (Kabir et al., 2018; Ferreira \& Cardoso, 2020; Silva \& Sousa, 2020; Calca et al., 2021).

A energia solar é responsável, diretamente ou indiretamente, pela geração de outras fontes energética, como é o caso da energia eólica. Uma vez que, parte das correntes de ventos são formadas pelo aquecimento desuniforme da superfície terrestre e da massa de ar, o qual provoca movimentos convectivos, sendo possível assim dizer que a energia eólica é uma manifestação indireta da energia solar (Lutgens, Tarbuck \& Tasa, 2015; Modi et al., 2017).

O crescente aumento da população mundial implicou no aumento da demanda energética. Os avanços do setor industrial necessários para suprir as demandas de mercado, acarretou no aumento das emissões de gases poluentes. Nesse sentido, as energias renováveis têm um papel fundamental para com a redução das emissões de gases que intensificam o efeito estufa (Shyam et al., 2016; Jakhar, Soni \& Gakkhar, 2017; Silva et al., 2020).

As maiores aplicações da energia solar estão no aquecimento de água e na geração de energia elétrica (Shyam et al., 2016; Jakhar, Soni \& Gakkhar, 2017; Tripathi \& Tiwari, 2017). Entretanto, apesar da incessante busca pela geração de energia elétrica a partir de fontes limpas, a geração por meio da energia solar ainda é pequena na matriz energética mundial (Meneguzzo et al., 2015; Li et al., 2018), isso se deve, principalmente, pela baixa eficiência das células solares (geração direta) em relação as demais (Polman et al., 2016; Hazama et al., 2018). Para se estabelecer uma análise comparativa, a eficiência da geração hidrelétrica alcança níveis de 65\%, na termoelétrica de 40\% e na eólica em torno de 35\% (Kalogirou, 2009).

A eficiência da geração de energia fotovoltaica não depende exclusivamente da radiação solar. Essa é também influenciada pela reflexão da radiação nos módulos fotovoltaicos (PV), bem como o nível de purificação dos materiais semicondutores utilizados (Chow, 2010; Ghadiri et al., 2015). Somente cerca de 15 a 20\% dessa energia solar são utilizados na 
geração de energia elétrica, sendo o restante convertido em calor e/ou energia refletida. Tal fato explica o porquê do aquecimento dos módulos fotovoltaicos (Quaschning, 2005; Polman et al., 2016; Brahim \& Jemni, 2017; Sahota \& Tiwari, 2017; Hazama et al., 2018). Van Helden et al. (2004) e Tripathy et al. (2017) afirmam que a energia não utilizada pode fazer com que o módulo alcance temperaturas superiores à temperatura ambiente em $35^{\circ} \mathrm{C}$. Já Oh \& TamizhMani (2010) fala que dependendo do local, o módulo pode alcançar $90^{\circ} \mathrm{C}$, comprometendo significativamente seu desempenho.

Estudos a nível mundial, têm sido realizados, visando o aumento da eficiência das células fotovoltaicas, com maior sucesso no campo da descoberta de novos materiais (Sahota \& Tiwari, 2017; von Roedern \& Ullal, 2018). Alguns pesquisadores trabalham na otimização de geração de energia, por meio de: concentradores, sistemas de rastreamento solar do módulo fotovoltaico e sistemas de resfriamento do módulo, visto que a eficiência dos módulos reduz drasticamente com o aumento da temperatura (Cunow \& Giesler, 2001; Sreeraj et al., 2013; Gupta et al., 2017; Hasan \& Mekhilef, 2017; Quansah et al., 2017).

Outras formas de maximizar o aproveitamento da energia solar é através da utilização de sistemas híbridos. Um dos exemplos é o sistema designado de PV/T ou PVT, do inglês Photovoltaic/Thermal, onde o calor do módulo PV é utilizado para aquecimento do fluido refrigerante, por convecção e/ou condução (Pathak et al., 2014; Dimri et al., 2017). A primeira pesquisa em PVT foi desenvolvida em 1978 (Florschuetz, 1979; Nahar et al., 2017).

Os sistemas PVT mais simples desenvolvidos utilizaram fluxo de ar na parte inferior do módulo PV. Os sistemas mais eficientes e complexos utilizam um fluxo de água para refrigerar o módulo PV. Na grande maioria das vezes, a água aquecida é posteriormente utilizada em sistemas domésticos como, por exemplo, o de aquecimento de água utilizada para banho. Portanto, os sistemas PVT que se utilizam de água apresentam maior eficiência de conversão global, isso por conta da conversão da irradiação solar em energia elétrica e térmica (Sandnes \& Rekstad, 2002; Karimi et al., 2015).

Observando a importância de estudar o efeito da temperatura nos painéis fotovoltaicos, esse trabalho teve como objetivo a realização de um estudo comparativo do desempenho de sistema PV e um sistema híbrido PVT. Foram realizados vários testes dos dois sistemas, distribuídos em dias, analisando a potência, a eficiência e a energia produzida pelos sistemas.

\section{Materiais e Métodos}

Nessa seção serão apresentados os materiais, equipamentos e a metodologia utilizada para realização dos experimentos nos sistemas PV e PVT. Os ensaios foram realizados na Universidade Federal do Rio Grande do Norte - UFRN, campus sede, na cidade de Natal/RN, onde a latitude é de $05^{\circ} 45^{\prime}$ Sul, longitude $35^{\circ} 12^{\prime}$ 'Oeste e altitude de $31 \mathrm{~m}$. Os experimentos foram realizados entre os meses de setembro a novembro de 2016. Os dados foram coletados a cada hora, das $9 \mathrm{~h} 00$ às $14 \mathrm{~h} 00$.

\subsection{Construção e Montagem do Sistema Fotovoltaico (PV)}

Para suportar e facilitar a orientação do módulo fotovoltaico foi construído um suporte, fabricado com cantoneiras de 1" x 1/8" de aço SAE 1020, unidas por solda. O suporte/estrutura do PV (Figura 1) possibilita o ajuste do ângulo de incidência em $10^{\circ}, 15^{\circ}$ e $20^{\circ}$, tendo sido adotado o ângulo de $10^{\circ}$ (Khoo et al., 2014). Com auxílio de uma bússola o módulo PV foi posicionado para o Norte magnético. 
Figura 1. Bancada para ensaio do módulo PV.

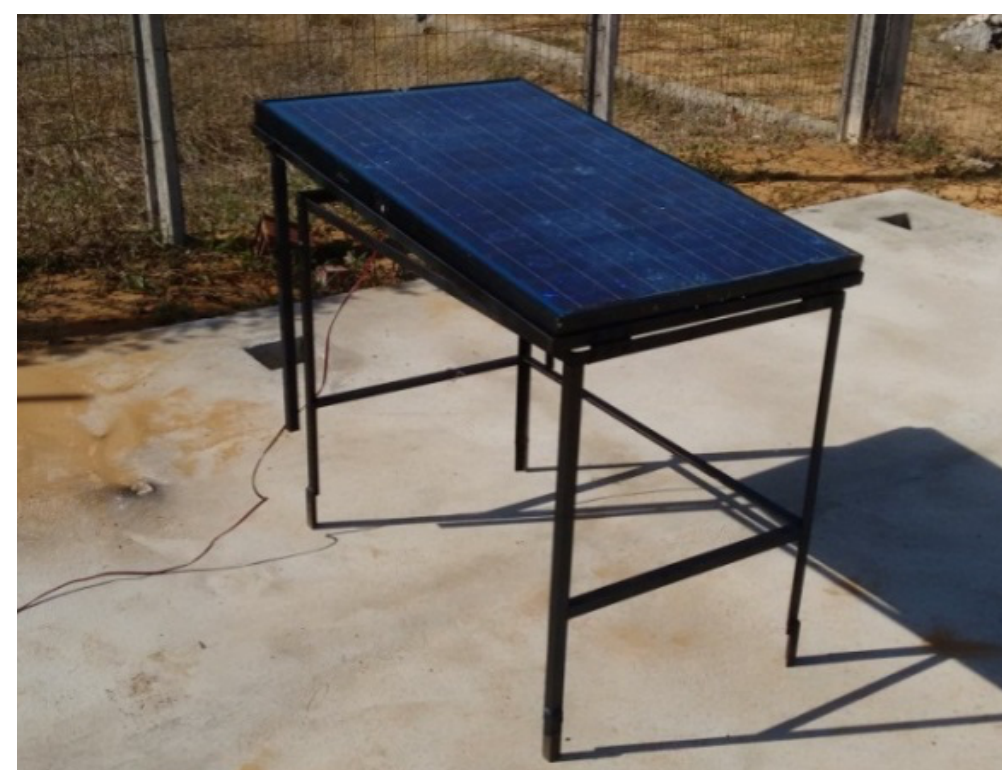

Fonte: Autores (2021).

O módulo fotovoltaico utilizado foi o modelo MSX 77, fabricado pela SOLAREX, composto por 36 células solares de silício policristalino, sendo sua superfície superior em vidro temperado com $3 \mathrm{~mm}$ de espessura e a superfície inferior em Tedlar. O mesmo apresenta dimensões externas de 1,1 $\mathrm{m}$ de comprimento, 0,65 $\mathrm{m}$ de largura e 0,05 $\mathrm{m}$ de espessura, com massa de 9,5 kg. Na Tabela 1 são apresentados os dados técnicos do módulo PV.

Tabela 1. Características Elétricas do Módulo MSX 77.

\begin{tabular}{cc}
\hline Potência de Pico $\left(P_{\text {máx }}\right)$ & $77 \mathrm{~W}$ \\
\hline Tensão de Potência de Pico $\left(V_{M P}\right)$ & $16,9 \mathrm{~V}$ \\
\hline Corrente de Potência de Pico $\left(I_{M P}\right)$ & $4,56 \mathrm{~A}$ \\
\hline Eficiência Máxima $\left(\eta_{\text {máx }}\right)$ & $10,8 \%$ \\
\hline Tensão de circuito Aberto $\left(V_{C A}\right)$ & $21,0 \mathrm{~V}$ \\
\hline Corrente de Curto Circuito $\left(I_{C C}\right)$ & $5,0 \mathrm{~A}$ \\
\hline Coeficiente $\alpha$ & $0,065 \pm 0,015 \% /{ }^{\circ} \mathrm{C}$ \\
\hline Coeficiente $\beta$ & $-(80 \pm 10) \mathrm{mV} /{ }^{\circ} \mathrm{C}$ \\
\hline Coeficiente $\gamma$ & $-(0,50 \pm 0,05) \% /{ }^{\circ} \mathrm{C}$ \\
\hline NOCT & $47 \pm 2{ }^{\circ} \mathrm{C}$ \\
\hline
\end{tabular}

Fonte: Adaptado de Solarex (1999).

\subsection{Construção e Montagem do Sistema PVT}

O sistema PVT utilizado nesse trabalho foi do tipo PVT-líquido, um módulo fotovoltaico com um coletor solar plano montado em sua face inferior. Desta forma, foi concebido um coletor tipo placa, cuja face inferior do módulo PV seria a face superior do coletor, facilitando a troca de calor do módulo PV com o líquido do coletor.

Para fabricar o coletor tipo placa foi utilizado uma chapa de acrílico com $4 \mathrm{~mm}$ de espessura, respeitando o espaço entre a face superior (face inferior do módulo PV) e inferior do coletor também de $4 \mathrm{~mm}$, sendo essa espessura da lâmina de água que percorria o coletor. As chapas foram cortadas a laser com uma geometria que revestisse o máximo possível a face inferior do módulo PV. As chapas de acrílico foram coladas na face inferior do módulo PV (Figura 2) com uma cola à base de poliuretano U-418, da marca BETASEAL. 
Figura 2. Coletor solar plano unido ao do módulo PV.

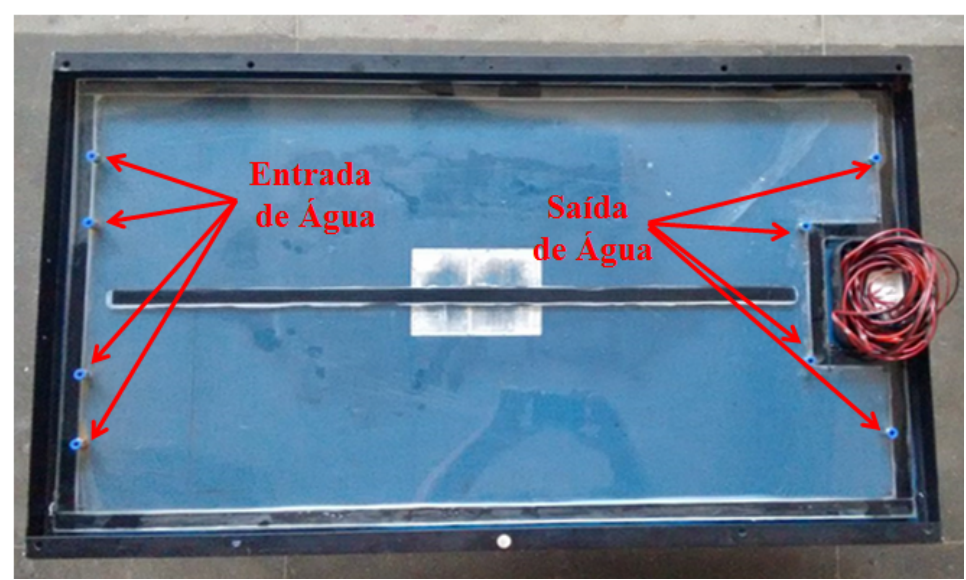

Fonte: Autores (2021).

Para que a cola não suportasse todo o peso do coletor e a força resultante da pressão da água, foram fabricados nove grampos com cantoneiras de 1" x 1/8" e barras chatas de 1" x 1/8", ambas de aço SAE 1020, esses grampos prenderam e prensaram o coletor contra o módulo $\mathrm{PV}$, fazendo a cola atuar apenas como elementos de estanqueidade da água.

As tomadas de entrada e saída de água foram montadas na superfície inferior do coletor, sendo quatro tomadas para entrada e quatro para a saída (Figura 2). As conexões utilizadas foram do tipo engate rápido (mangueiras pneumáticas de 6,0 $\mathrm{mm}$ ) com a extremidade roscada (rosca 1/8" BSP inglesa) para fixação no acrílico, cuja vedação foi feita por o-rings.

A alimentação da água se deu na parte mais baixa do PVT e a saída na parte mais elevada. A alimentação foi do tipo forçada por gravidade e com sistema aberto, ou seja, a água aquecida pelo PVT não foi mais utilizada na alimentação no sistema. A fonte de água utilizada foi um reservatório de polietileno, com capacidade volumétrica de 200 litros.

Foram realizados ensaios para determinar o desnível entre o módulo PV e a superfície da água do reservatório, de tal forma que proporcionasse uma vazão média de, aproximadamente, $20 \mathrm{l} / \mathrm{h}(\mathrm{kg} / \mathrm{h})$. O procedimento consistiu em encher o reservatório até certo nível e medir o volume de líquido escoado no tempo de 30 minutos. O desnível que proporcionou a vazão desejada foi de aproximadamente $0,77 \mathrm{~m}$ (Figura 3). Portanto, durante a realização de todos os testes do PVT, o reservatório foi reabastecido a cada 30 minutos, para que a vazão média fosse mantida aproximadamente constante. 
Figura 3. Aparato experimental utilizados nos ensaios do sistema PVT.

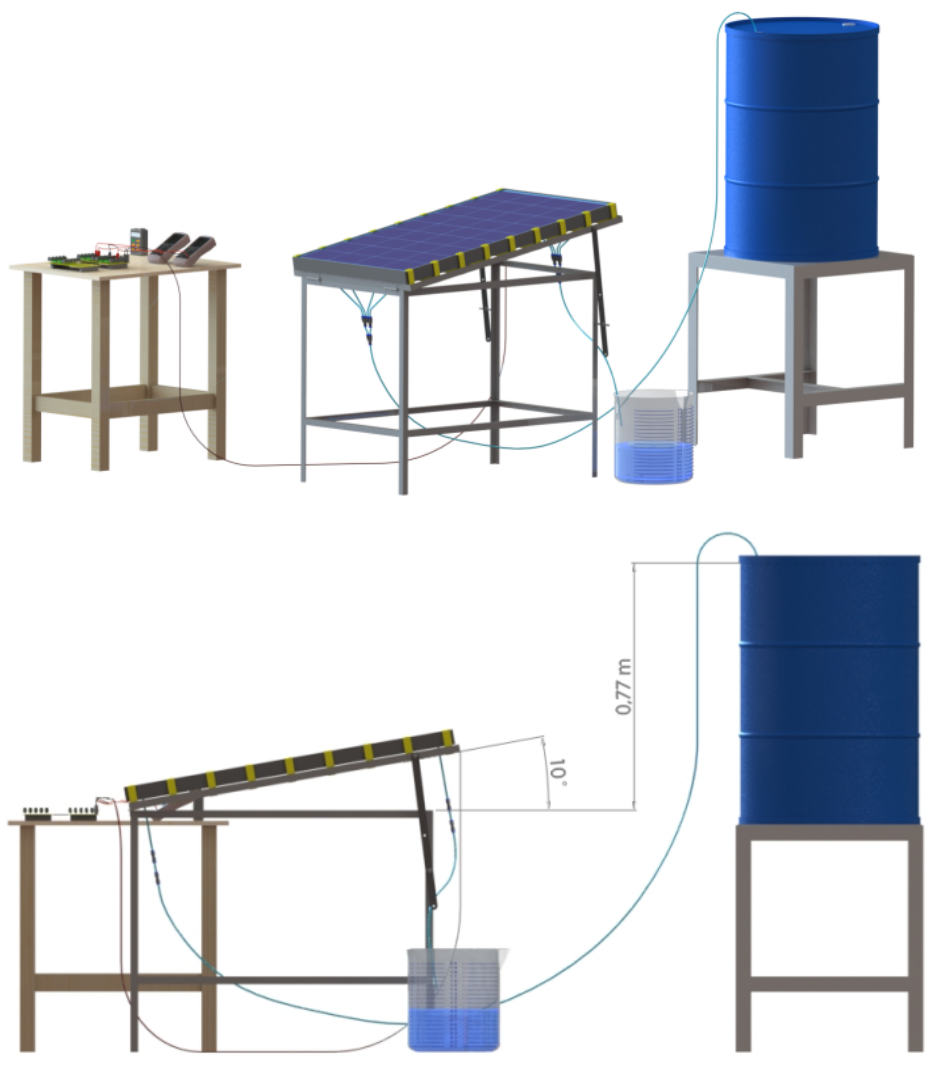

Fonte: Autores (2021).

\subsection{Determinação da Potência e Eficiência do Módulo PV}

Os parâmetros elétricos analisados foram a máxima potência gerada pelo módulo PV e a máxima eficiência de conversão de energia. Para determinar a máxima potência gerada foi necessário primeiro coletar dados para traçar a curva característica I $\mathrm{x}$ V (corrente versus tensão) do módulo PV para cada condição operacional.

De posse da curva de I x V, foi traçada a curva de $\mathrm{P}$ x V (potência versus tensão), podendo se determinar a máxima potência elétrica gerada pelo módulo PV, para cada condição operacional. A máxima eficiência do módulo PV é determinada conforme a Equação 1.

$$
\eta_{\text {Elét. }}=\frac{P_{\text {máx. }}}{I_{G} \cdot A}
$$

Onde:

$I_{G}:$ é a irradiância solar global $\left(\mathrm{W} / \mathrm{m}^{2}\right)$;

$A$ : é a área da superfície superior do módulo fotovoltaico $\left(\mathrm{m}^{2}\right)$.

Para coletar dados de corrente e tensão e esboçar a curva I x V, foi necessário desenvolver um banco de carga formado por chaves comutadoras e resistores de potência. Para cada valor de resistência obteve-se medidas de corrente e tensão associadas, onde foram utilizados dois multímetros digitais (Modelo A9 da marca Politerm) para tal finalidade.

A Figura 4 mostra, de forma esquemática, o arranjo elétrico do banco de carga, multímetros (voltímetro e amperímetro) e módulo fotovoltaico. Na Figura 5 é ilustrado o banco de carga fabricado conforme arranjo elétrico proposto. 
Figura 4. Diagrama elétrico do banco de carga.

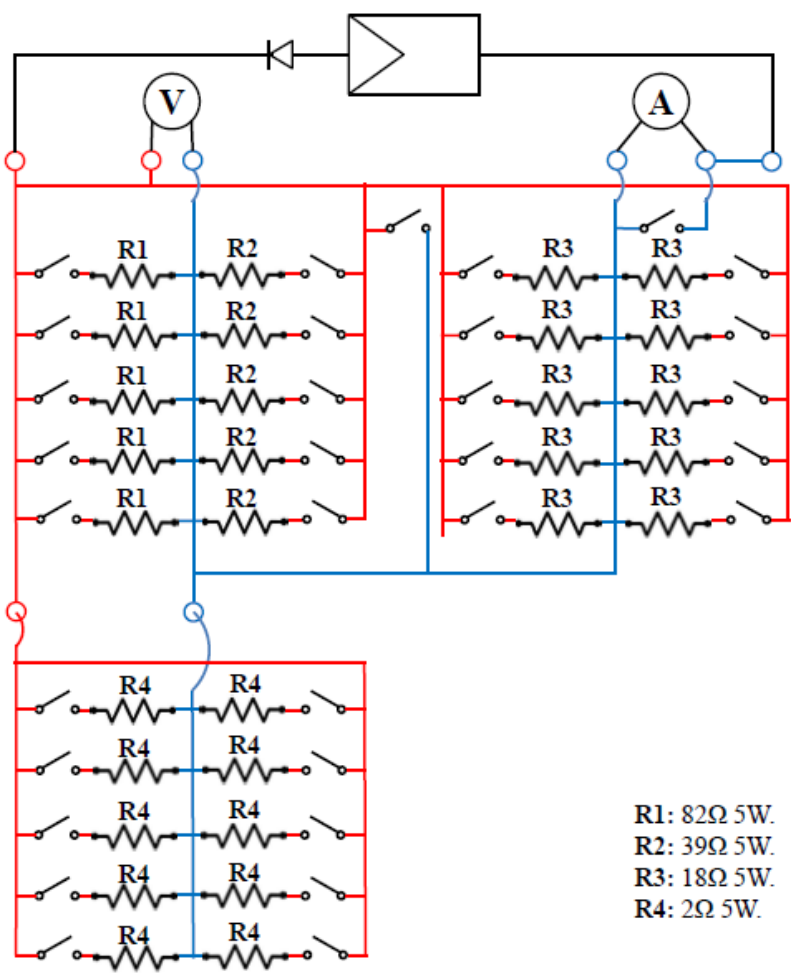

Fonte: Autores (2021).

Figura 5. Banco de carga construído.

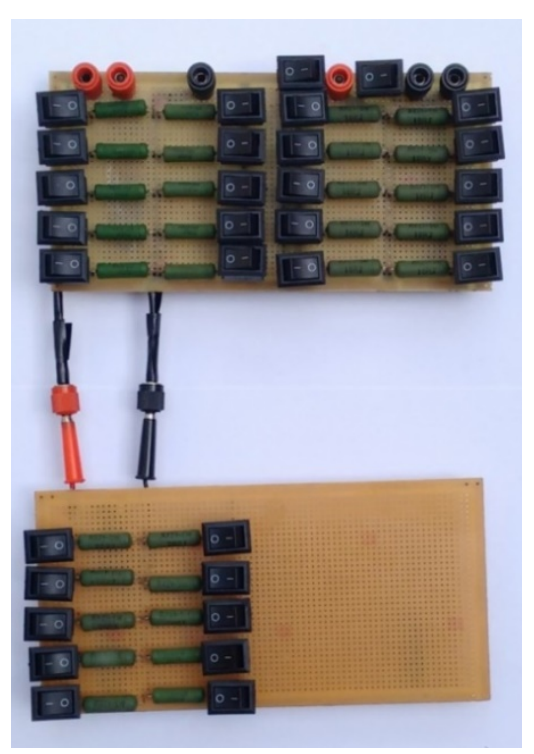

Fonte: Autores (2021).

Os dados de tensão e corrente (Figura 6), coletados no banco de carga, foram utilizados para determinar a potência elétrica máxima gerada pelo painel fotovoltaico. A irradiância solar global foi medida no local do PV, com o Piranômetro TES1333 (range de $2000 \mathrm{~W} / \mathrm{m}^{2}$, resolução de $0,1 \mathrm{~W} / \mathrm{m}^{2}$, resposta espectral de 400 a $1100 \mathrm{~nm}$, exatidão de $\pm 10 \mathrm{~W} / \mathrm{m}^{2}$ ) apontado para o céu, na vertical. 
Figura 6. Curvas I x V e P x V do Módulo MSX 77 para uma radiação solar global de $660 \mathrm{~W} / \mathrm{m}^{2}$.

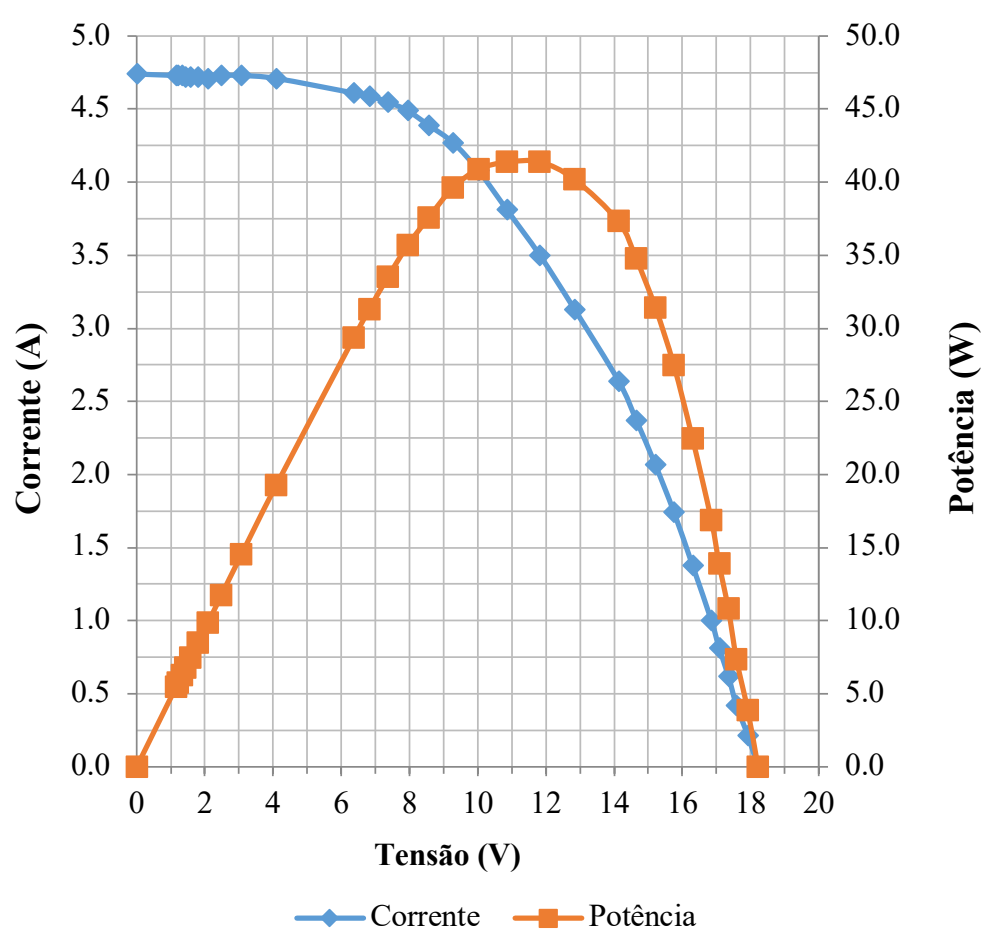

Fonte: Autores (2021).

\subsubsection{Quantificação da Energia Produzida pelo Módulo PV}

Como citado no começo dessa seção, os dados coletados foram pontuais, no entanto, devido à variação continua da radiação e, por consequência, da potência e eficiência, foram adotados dados discretos (valores médios para cada intervalo de tempo de 1 hora) para quantificar a energia produzida pelos sistemas.

A irradiância solar global média incidente ( $I_{G}$ média) foi obtida a partir da estação meteorológica Natal-A304, código OMM 81839, do INMET - Instituto Nacional de Meteorologia, localizada no Campus Central da UFRN (Tabela 2 e 3). A eficiência média para cada intervalo de tempo foi igual a média aritmética dos dados coletados no início e fim do intervalo de tempo. A energia produzida no intervalo de tempo foi o produto da irradiância solar global média com a eficiência média no intervalo de tempo. O somatório da energia gerada em cada intervalo foi considerado como a geração diária, expressa em W.h.

\subsection{Determinação da Potência e Eficiência do Sistema PVT}

O sistema PVT é formado pelos subsistemas elétrico e térmico. A parcela da energia referente ao sistema elétrico (módulo PV) foi quantificada como descrito na seção 2.3.

Para determinar as parcelas referentes ao sistema térmico, o procedimento adotado foi o mesmo daquele utilizado nos coletores solares planos do tipo placa. A potência térmica foi determinada pela Equação 2. Para tal, tornou-se necessário quantificar a vazão de água que flui no coletor e a diferença de temperatura média da mesma no intervalo de tempo.

$$
P_{\text {Térm. }}=\dot{m} \cdot c_{p} \cdot(\overline{\Delta T})
$$

Onde:

$P_{\text {Térm. }}$ : é a potência térmica $(\mathrm{W})$;

$\dot{m}$ : é a vazão mássica $(\mathrm{kg} / \mathrm{s})$; 
$c_{p}$ : é o calor especifico da água a pressão constante $\left(4178 \mathrm{~J} / \mathrm{kg} .{ }^{\circ} \mathrm{C}\right)$;

$\overline{\Delta T}$ : é a média da diferença de temperatura da saída e entrada da água, em um intervalo de tempo $\left({ }^{\circ} \mathrm{C}\right) ;$

A vazão de água foi mensurada de forma análoga à descrita na seção 2.2. Foram utilizados dois reservatórios, um com capacidade volumétrica de 20 litros (com graduação a cada 1 litro) e outro com capacidade volumétrica de $600 \mathrm{ml}$ (graduação a cada $25 \mathrm{ml}$ ). Também foi utilizado um cronômetro.

A vazão média foi quantificada a cada hora, o reservatório foi reabastecido até o nível pré-determinado a cada 30 minutos e as temperaturas de entrada e saída da água foram medidas a cada 1 hora por dois termômetros digitais com sonda termopar de cromel-alumel.

\subsection{Quantificação da Energia Produzida pelo Sistema PVT}

Assim como na seção 2.3.1, aqui também foram adotados dados discretos. A irradiância solar média incidente utilizada para os cálculos também foi obtida pela estação meteorológica Natal-A304. A potência térmica calculada foi média, visto que o cálculo envolve a vazão média e a diferença de temperaturas médias de cada intervalo de tempo analisado. A eficiência média para cada intervalo de tempo do sistema PVT foi calculada através da soma das parcelas elétrica e térmica; o somatório das energias produzidas em cada intervalo também foi a energia produzida por dia, expressa em W.h.

\section{Resultados e Discussão}

Nesta secção são analisados os resultados obtidos nos experimentos, sendo realizadas análises das potências elétrica e térmica, assim como, da eficiência e da energia produzida pelos sistemas PV e PVT.

\subsection{Análise e Seleção dos Dias de Ensaios}

Dentre o período de ensaios dos sistemas, foram selecionados três dias para cada sistema, de tal maneira que as condições solarimétricas fossem as mais próximas possíveis. Os dados de irradiância solar global média para os dias de ensaio selecionados são apresentados nas Tabelas 2 e 3.

Tabela 2. Radiações globais para os dias de ensaios selecionados do sistema PV.

\begin{tabular}{|c|c|c|c|c|c|}
\hline \multicolumn{6}{|c|}{ SISTEMA PV } \\
\hline \multirow{2}{*}{$\begin{array}{l}\text { Período } \\
\text { (horas) }\end{array}$} & \multicolumn{3}{|c|}{$\begin{array}{c}I_{G} \text { média do INMET } \\
\left(\mathbf{W} / \mathbf{m}^{2}\right)\end{array}$} & \multirow{2}{*}{$\begin{array}{c}\text { Média } \\
\text { dos } \\
\text { Dias } \\
\left(\mathbf{W} / \mathbf{m}^{2}\right) \\
\end{array}$} & \multirow{2}{*}{$\begin{array}{c}\text { Desvio } \\
\text { Percentual }\end{array}$} \\
\hline & Dia A & Dia B & Dia C & & \\
\hline 09:00 - 10:00 & 906,1 & 845,6 & 940,3 & 897,3 & $5,35 \%$ \\
\hline 10:00 - 11:00 & 980,3 & 1014,4 & 1027,5 & 1007,4 & $2,42 \%$ \\
\hline 11:00 - 12:00 & 1010,3 & 1040,8 & 1003,3 & 1018,1 & $1,96 \%$ \\
\hline $12: 00-13: 00$ & 943,3 & 967,5 & 913,3 & 941,4 & $2,88 \%$ \\
\hline $13: 00-14: 00$ & 802,2 & 833,6 & 793,1 & 809,6 & $2,63 \%$ \\
\hline
\end{tabular}

Fonte: Autores (2021). 
Tabela 3. Radiações globais para os dias de ensaios selecionados do sistema PVT.

\begin{tabular}{|c|c|c|c|c|c|}
\hline \multicolumn{6}{|c|}{ SISTEMA PVT } \\
\hline \multirow{2}{*}{$\begin{array}{l}\text { Período } \\
\text { (horas) }\end{array}$} & \multicolumn{3}{|c|}{$\begin{array}{c}I_{G} \text { média do INMET } \\
\left(\mathbf{W} / \mathbf{m}^{2}\right)\end{array}$} & \multirow{2}{*}{$\begin{array}{c}\text { Média } \\
\text { dos } \\
\text { Dias } \\
\left(\mathbf{W} / \mathbf{m}^{2}\right)\end{array}$} & \multirow{2}{*}{$\begin{array}{c}\text { Desvio } \\
\text { Percentual }\end{array}$} \\
\hline & Dia D & Dia E & Dia F & & \\
\hline 09:00 - 10:00 & 916,4 & 905,8 & 871,4 & 897,9 & $2,62 \%$ \\
\hline 10:00 - 11:00 & 993,1 & 987,2 & 977,8 & 986,0 & $0,78 \%$ \\
\hline 11:00 - 12:00 & 1010,0 & 1020,6 & 1023,1 & 1017,9 & $0,68 \%$ \\
\hline 12:00 - 13:00 & 924,2 & 942,5 & 936,4 & 934,4 & $1,00 \%$ \\
\hline 13:00 - 14:00 & 821,1 & 813,3 & 773,1 & 802,5 & $3,21 \%$ \\
\hline
\end{tabular}

Fonte: Autores (2021).

Para o sistema PV a irradiância solar global média teve como maior desvio padrão percentual um valor na ordem dos 5\%. Já para o sistema PVT, o desvio padrão percentual foi menor, na ordem dos $3 \%$.

Os valores medidos de irradiância média dos dias foram de $934,8 \mathrm{~W} / \mathrm{m}^{2}$ e $927,8 \mathrm{~W} / \mathrm{m}^{2}$ para os sistemas PV e PVT, respectivamente. Essa pequena variação justifica/viabiliza a utilização desses dados para análise dos sistemas, visto que a variação é pequena, inferior a $1 \%$.

\subsection{Resultados da Potência Elétrica do Sistema PV e PVT}

Com os dados de tensão e corrente, coletados com auxílio do banco de carga e dos multímetros, foram esboçadas as curvas de I x V e, em seguida, a de P x V. A partir do valor de máxima potência (obtida pela curva de P x V) e da irradiância solar instantânea, foi calculada a eficiência de conversão de energia solar em elétrica (Equação 1). Os valores das eficiências para cada hora e dia são apresentados nas Figuras 7 e 8.

Figura 7. Eficiências elétricas para o sistema PV.

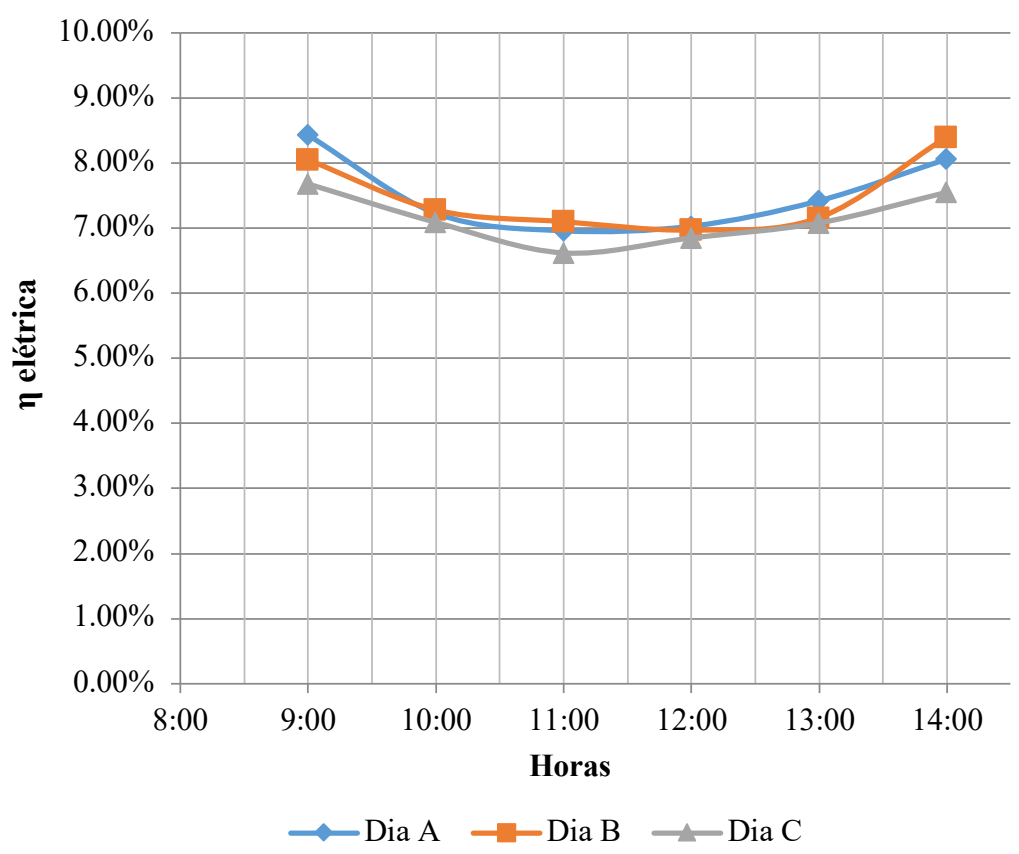

Fonte: Autores (2021). 
Figura 8. Eficiências elétricas para o sistema PVT.

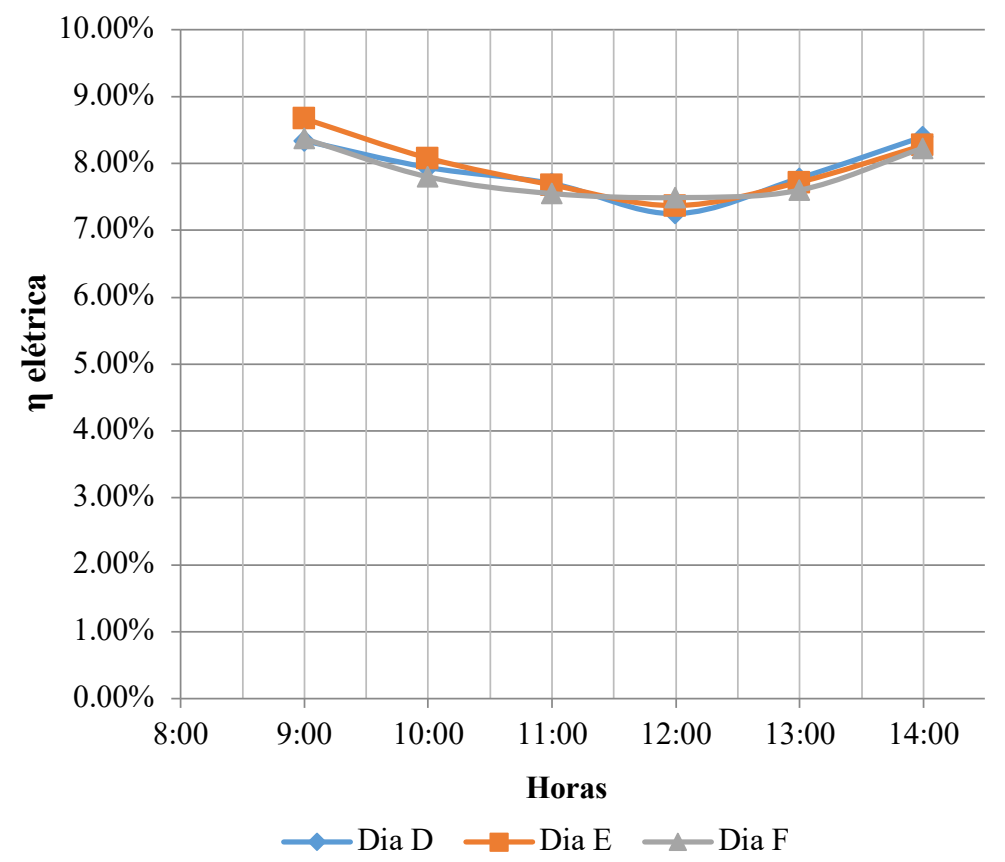

Fonte: Autores (2021).

O grau de dispersão do sistema PV foi maior que o do sistema PVT, fato justificado pelo maior desvio padrão da irradiância solar global (Tabelas 2 e 3).

Na Figura 9 são representadas as médias das eficiências elétricas pontuais para os três dias de ensaio nos dois sistemas analisados. Na Figura 10 é apresentada a eficiência média para cada intervalo de tempo. Esses dados, juntamente com as radiações globais médias (Tabelas 2 e 3) foram usados para determinar a potência elétrica produzida por intervalo de tempo, como exposto na Figura 11.

Figura 9. Média para cada hora das eficiências elétricas dos sistemas PV e PVT.

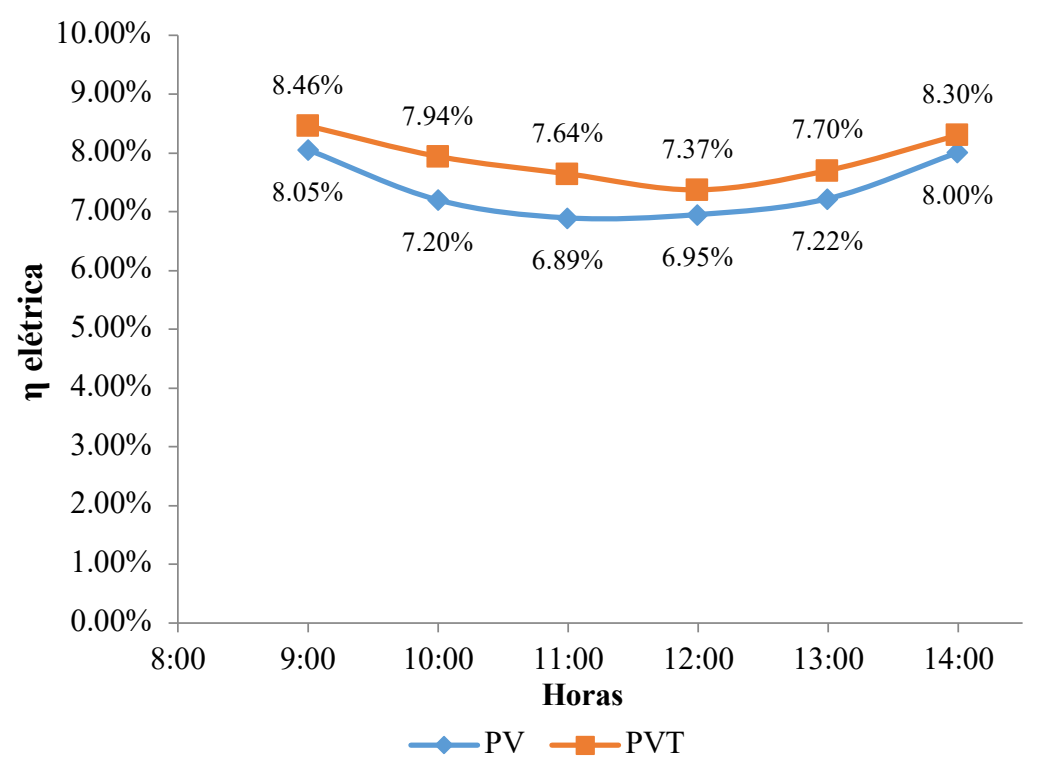

Fonte: Autores (2021). 
Figura 10. Eficiências elétricas discretas para o sistema PV e PVT.

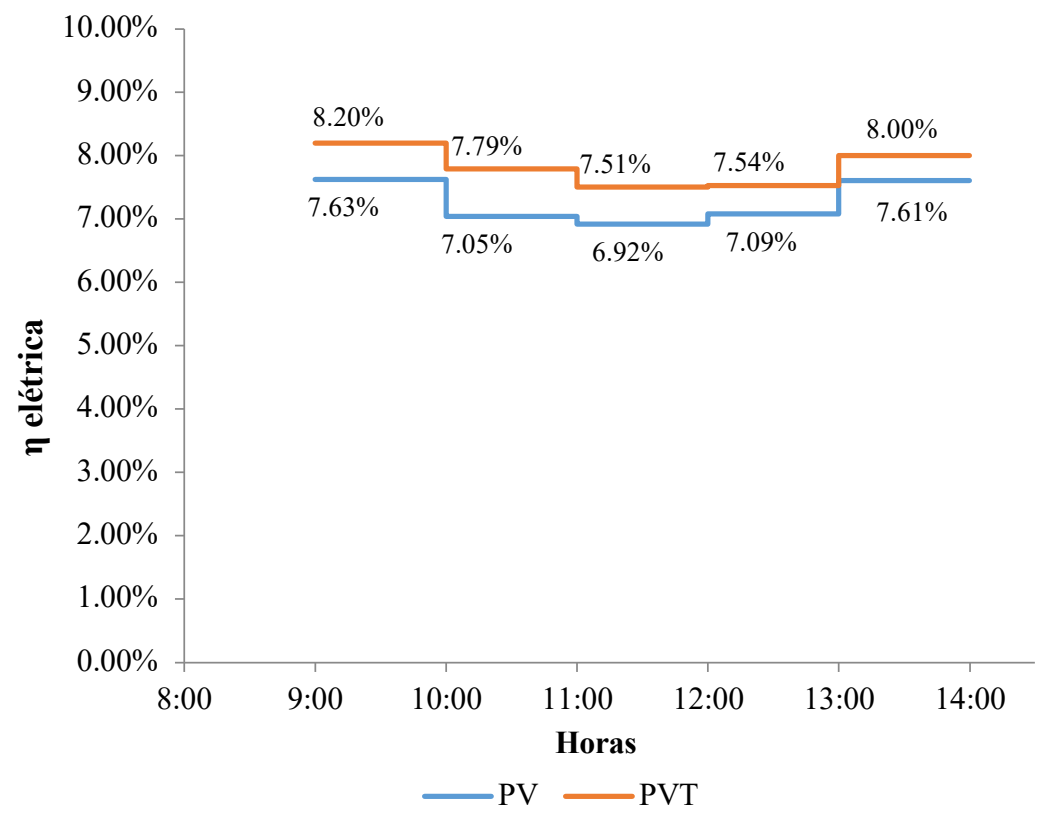

Fonte: Autores (2021).

O sistema PVT apresentou um aumento da eficiência elétrica do módulo PV, de 0,57\% para o intervalo das 09:00 às 10:00 horas; $0,74 \%$ para o intervalo de 10:00 às 11:00 horas, sendo esses os maiores aumentos de eficiência de conversão de energia solar em elétrica. A partir da 11:00 horas ocorreu uma redução na eficiência, com valor mínimo de 0,39\% no intervalo das 13:00 as 14:00 horas (Figura 10).

Na Figura 11 são apresentadas as potências elétricas médias para cada intervalo de tempo. As áreas desses gráficos são numericamente iguais à energia elétrica produzida durante um dia.

Figura 11. Potência elétrica média gerada ao longo do dia para o sistema PV e PVT.

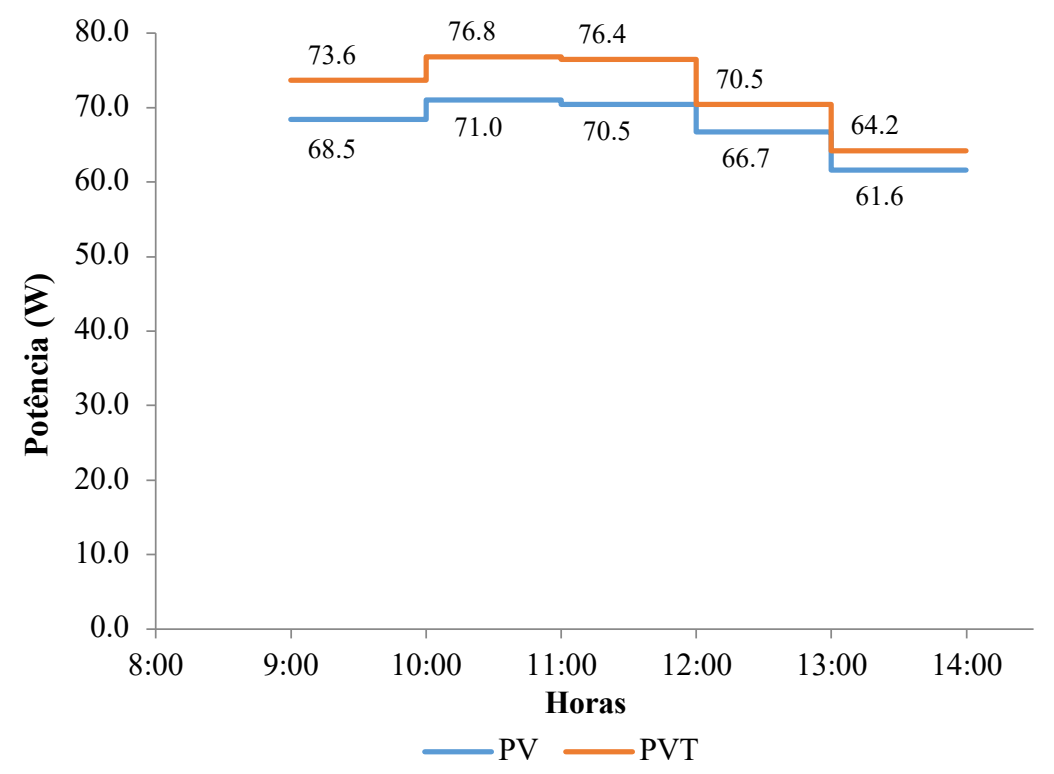

Fonte: Autores (2021). 
A potência elétrica média gerada pelo sistema PVT foi superior em todos os intervalos de hora do dia. O maior acréscimo de potência elétrica correu para o intervalo das 10:00 às 11:00 horas, sendo de 5,98 W.h. A energia elétrica diária produzida pelo sistema PV foi de 338,3 W.h, enquanto que o sistema PVT gerou 361,5 W.h.

O sistema PVT apresentou um aumento de 23,2 W.h, correspondente a 6,86\%. Resultado próximo ao de Sardarabadi, Passandideh-Fard e Zeinali Heris (2014), cuja vazão de água foi de $40 \mathrm{~kg} / \mathrm{h}$, justificando o seu maior ganho. Já Bahaidarah et al. (2013) apresentaram um ganho na ordem dos 9\% utilizando-se de uma vazão de ensaio de 216 kg/h, ou seja, vazão aproximadamente 10 vezes superior à utilizada nesse trabalho, acarretando assim, por consequência, numa maior extração de calor do módulo PV e maior eficiência elétrica.

\subsection{Resultados da Potência Térmica do Sistema PVT}

Na Tabela 4 estão apresentados, por hora, os dados de temperatura da água que fluiu pelo PVT. Na Tabela 5 são informadas as vazões médias e as variações de temperatura médias (calculadas com os dados da Tabela 4).

Tabela 4. Temperaturas da água de entrada e saída do PVT.

\begin{tabular}{ccccccc}
\hline \multirow{2}{*}{ Hora } & \multicolumn{2}{c}{ Dia D } & \multicolumn{2}{c}{ Dia E } & \multicolumn{2}{c}{ Dia F } \\
\cline { 2 - 7 } & $\begin{array}{c}\text { T Ent. } \\
\left({ }^{\circ} \mathbf{C}\right)\end{array}$ & $\begin{array}{c}\text { T Saí. } \\
\left({ }^{\circ} \mathbf{C}\right)\end{array}$ & $\begin{array}{c}\text { T Ent. } \\
\left({ }^{\circ} \mathbf{C}\right)\end{array}$ & $\begin{array}{c}\text { T Saí. } \\
\left({ }^{\circ} \mathbf{C}\right)\end{array}$ & $\begin{array}{c}\text { T Ent. } \\
\left({ }^{\circ} \mathbf{C}\right)\end{array}$ & $\begin{array}{c}\text { T Saí. } \\
\left({ }^{\circ} \mathbf{C}\right)\end{array}$ \\
\hline $\mathbf{0 9 : 0 0}$ & 29,7 & 41,4 & 30,5 & 40,9 & 30,9 & 41,8 \\
\hline $\mathbf{1 0 : 0 0}$ & 30,9 & 43,8 & 31,2 & 44,6 & 31,6 & 42,9 \\
\hline $\mathbf{1 1 : 0 0}$ & 31,9 & 46,0 & 32,1 & 46,2 & 32,3 & 46,2 \\
\hline $\mathbf{1 2 : 0 0}$ & 32,5 & 46,1 & 32,9 & 46,5 & 32,4 & 46,3 \\
\hline $\mathbf{1 3 : 0 0}$ & 33,1 & 44,3 & 33,3 & 45,1 & 33,5 & 45,6 \\
\hline $\mathbf{1 4 : 0 0}$ & 33,8 & 42,3 & 33,9 & 43,0 & 34,0 & 43,1 \\
\hline
\end{tabular}

Fonte: Autores (2021).

Tabela 5. Vazões e variação de temperatura média da água que fluía pelo sistema PVT.

\begin{tabular}{ccccccc}
\hline \multirow{2}{*}{ Hora } & \multicolumn{2}{c}{ Dia D } & \multicolumn{2}{c}{ Dia E } & \multicolumn{2}{c}{ Dia F } \\
\cline { 2 - 7 } & $\begin{array}{c}\mathbf{m} \\
(\mathbf{k g} / \mathbf{h})\end{array}$ & $\begin{array}{c}\overline{\Delta \boldsymbol{T}} \\
\left({ }^{\circ} \mathbf{C}\right)\end{array}$ & $\begin{array}{c}\mathbf{m} \\
(\mathbf{k g} / \mathbf{h})\end{array}$ & $\begin{array}{c}\overline{\Delta \boldsymbol{T}} \\
\left({ }^{\circ} \mathbf{C}\right)\end{array}$ & $\begin{array}{c}\dot{\mathbf{m}} \\
(\mathbf{k g} / \mathbf{h})\end{array}$ & $\begin{array}{c}\overline{\Delta \boldsymbol{T}} \\
\left({ }^{\circ} \mathbf{C}\right)\end{array}$ \\
\hline $\mathbf{0 9 : 0 0}-\mathbf{1 0 : 0 0}$ & 20,9 & 12,3 & 20,0 & 11,9 & 19,2 & 11,1 \\
\hline $\mathbf{1 0 : 0 0}-\mathbf{1 1 : 0 0}$ & 20,3 & 13,5 & 19,7 & 13,8 & 19,2 & 12,6 \\
\hline $\mathbf{1 1 : 0 0}-\mathbf{1 2 : 0 0}$ & 19,8 & 13,9 & 19,6 & 13,9 & 19,4 & 13,9 \\
\hline $\mathbf{1 2 : 0 0}-\mathbf{1 3 : 0 0}$ & 20,0 & 12,4 & 19,3 & 12,7 & 19,3 & 13,0 \\
\hline $\mathbf{1 3 : 0 0}-\mathbf{1 4 : 0 0}$ & 19,9 & 9,9 & 19,6 & 10,5 & 19,3 & 10,6 \\
\hline
\end{tabular}

Fonte: Autores (2021).

As vazões apresentadas na Tabela 5, não corresponderam sempre aos $20 \mathrm{~kg} / \mathrm{h}$ pretendidos. Porém, a variação ao longo do dia foi pequena, sendo as vazões médias de 20,2 kg/h,19,6 kg/h e 19,3 kg/h, para primeiro, segundo e terceiro dias, respectivamente.

Com os dados da Tabela 5 foram calculadas as potências térmicas médias para cada intervalo de tempo. Na Figura 12 são apresentadas as potências térmicas médias para os três dias de ensaios. As eficiências térmicas médias (Figura 13) foram calculadas com os dados da Figura 12 e as radiações médias globais da Tabela 3. 
Figura 12. Potência térmica média do sistema PVT ao longo do dia.

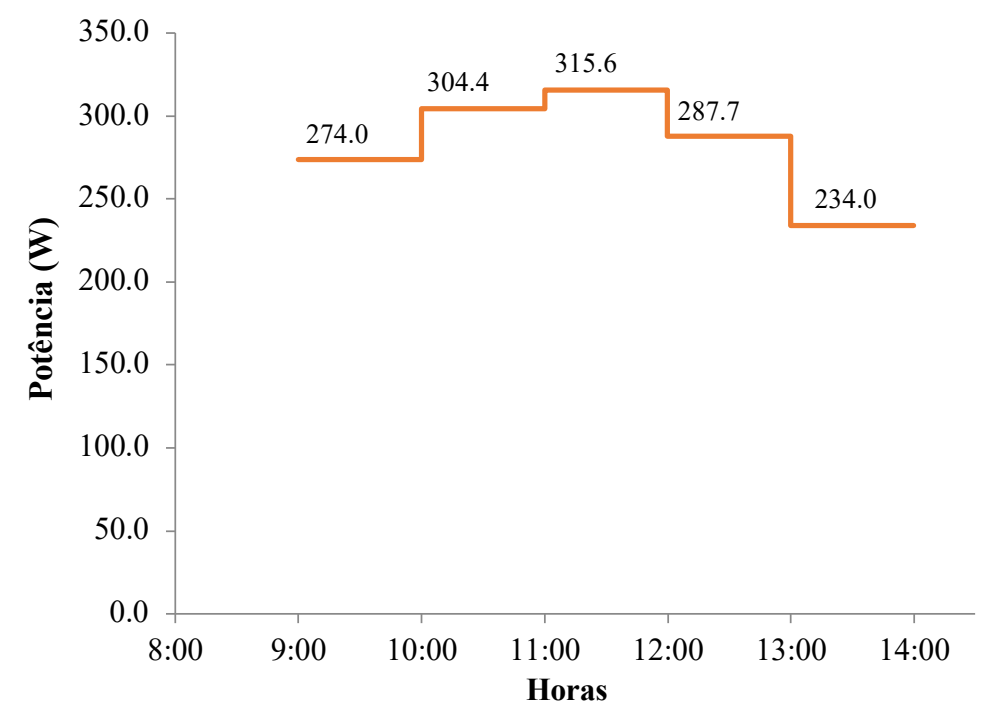

Fonte: Autores (2021).

Figura 13. Eficiência térmica média do sistema PVT ao longo do dia.

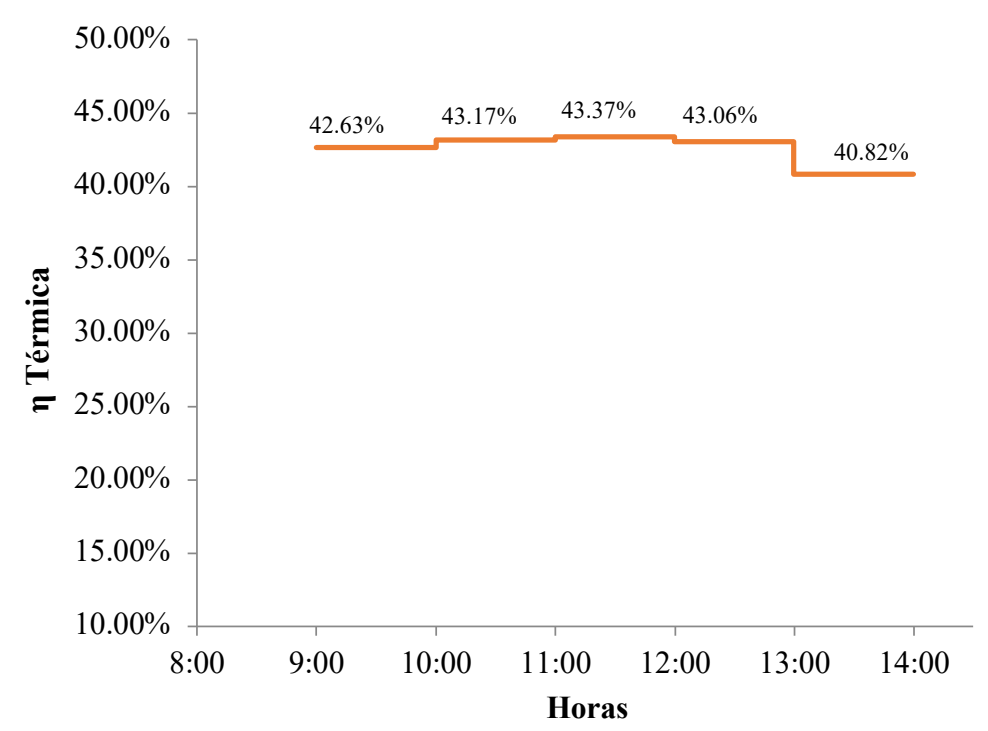

Fonte: Autores (2021).

Assim como a diferença de temperatura média de entrada e saída da água, a potência térmica média gerada também apresentou um crescimento até o intervalo das 11:00 às 12:00 horas, apresentando um decrescimento a partir desse intervalo.

O maior gradiente de temperatura médio da água e a máxima geração foram de $13,9^{\circ} \mathrm{C}$ e $315,6 \mathrm{~W} . h$, respectivamente, com irradiância solar média global de $1017,9 \mathrm{~W} / \mathrm{m}^{2}$, resultando em uma eficiência de 43,37\%. A mínima potência média gerada foi 234,0 W, entre às 13:00 e 14:00 horas, e a segunda menor potência foi de 274,0 W, entre às 09:00 e 10:00 horas.

A energia média produzida pelo sistema térmico durante um dia foi de 1415,7 W.h, quantidade superior em 291,6\% à quantidade de energia elétrica produzida pelo módulo fotovoltaico no sistema PVT, que foi de 361,5 W.h (Figura 11).

A eficiência média do sistema térmico foi de 42,61\%, próxima da obtida por Gang et al. (2011), o qual alcançou o valor de 41,9\%. Esses valores são inferiores à eficiência de coletores solares planos comerciais, que apresentam eficiência na ordem 
dos 50\% (Yandri, 2017). A eficiência global do sistema PVT obtida foi em torno de 50\%, próxima da eficiência de 51,3\% obtida por Gang et al. (2011), mas inferior aos 64,3\% e 68,4\% obtidos por Ghadiri et al. (2015) e Fudholi et al. (2014), respectivamente.

O menor valor de eficiência é justificado pela maior perda térmica do coletor utilizado no sistema PVT, visto que o mesmo não apresentava isolamento térmico. Coletores comerciais tradicionalmente apresentam um isolamento térmico de lã de vidro, lã de rocha e ou espuma de poliuretano, reduzindo consideravelmente as perdas térmicas.

\section{Conclusão}

Ficou comprovado que a redução da temperatura do módulo PV provocou um aumento da eficiência elétrica, registrando um aumento na ordem dos 7\%. O aumento da efíciência elétrica proporcionou um ganho médio de 23,2 W.h/dia, o que corresponde a um aumento de $6,86 \%$ na energia elétrica média gerada.

O sistema PVT produziu uma energia térmica diária média de 1415,7 W.h, valor superior em 291,6\% a energia elétrica produzida pelo módulo fotovoltaico no mesmo sistema. $\mathrm{O}$ estudo mostrou que, mesmo sem a utilização de um sistema de isolamento térmico robusto, foi possível obter um nível de eficiência global próxima das obtidas nos trabalhos de Gang et al. (2011), Fudholi et al. (2014) e Ghadiri et al. (2015).

Ficou comprovado que o sistema PVT é viável e pode ser utilizado em sistemas domésticos/residenciais, fornecendo água aquecida para o banho. Podendo também ser utilizados em aplicações industriais, como no pré-aquecimento da água que alimenta uma caldeira.

\section{Referências}

Al-Nimr, M., \& Qananba, K. (2018). A solar hybrid system for power generation and water distillation. Solar Energy, 171, 92-105. https://doi.org/10.1016/j.solener.2018.06.019

Bahaidarah, H., Subhan, A., Gandhidasan, P., \& Rehman, S. (2013). Performance evaluation of a PV (photovoltaic) module by back surface water cooling for hot climatic conditions. Energy, 59, 445-453. https://doi.org/10.1016/j.energy.2013.07.050

Brahim, T., \& Jemni, A. (2017). Economical assessment and applications of photovoltaic/thermal hybrid solar technology: A review. Solar Energy, 153, 540561. https://doi.org/10.1016/j.solener.2017.05.081

Calca, M. V. C., Raniero, M. R., Anacleto, K. B., Franco, J. R., Dal Pai, A., \& Caneppele, F. de L. (2021). Uma perspectiva sobre o aproveitamento térmico e a conversão direta da energia solar em áreas rurais no Brasil. Research, Society and Development, 10(6), e9810615610. https://doi.org/10.33448/rsd-v10i6.15610

Chow, T. (2010). A review on photovoltaic/thermal hybrid solar technology. Applied Energy, 87(2), 365-379. https://doi.org/10.1016/j.apenergy.2009.06.037

Cunow, E., \& Giesler, B. (2001). The megawatt solar roof at the new Munich Trade Fair Centre - an advanced and successful new concept for PV plants in the megawatt range. Solar Energy Materials and Solar Cells, 67(1-4), 459-467. https://doi.org/10.1016/s0927-0248(00)00315-9

Dimri, N., Tiwari, A., \& Tiwari, G. (2017). Thermal modelling of semitransparent photovoltaic thermal (PVT) with thermoelectric cooler (TEC) collector. Energy Conversion and Management, 146, 68-77. https://doi.org/10.1016/j.enconman.2017.05.017

Ferreira, M. A. M., \& Cardoso, R. B. (2020). Impactos energéticos e ambientais do uso de sistemas solares fotovoltaicos para carregamento de carros elétricos em postos de abastecimento no Brasil. Research, Society and Development, 9(9), e767997749. https://doi.org/10.33448/rsd-v9i9.7749

Florschuetz, L. (1979). Extension of the Hottel-Whillier model to the analysis of combined photovoltaic/thermal flat plate collectors. Solar Energy, 22(4), 361366. https://doi.org/10.1016/0038-092x(79)90190-7

Fudholi, A., Sopian, K., Yazdi, M., Ruslan, M., Ibrahim, A., \& Kazem, H. (2014). Performance analysis of photovoltaic thermal (PVT) water collectors. Energy Conversion and Management, 78, 641-651. https://doi.org/10.1016/j.enconman.2013.11.017

Gang, P., Huide, F., Tao, Z., \& Jie, J. (2011). A numerical and experimental study on a heat pipe PV/T system. Solar Energy, 85(5), 911-921. https://doi.org/10.1016/j.solener.2011.02.006

Ghadiri, M., Sardarabadi, M., Pasandideh-fard, M., \& Moghadam, A. (2015). Experimental investigation of a PVT system performance using nano ferrofluids. Energy Conversion and Management, 103, 468-476. https://doi.org/10.1016/j.enconman.2015.06.077

Gupta, N., Garg, R., \& Kumar, P. (2017). Sensitivity and reliability models of a PV system connected to grid. Renewable And Sustainable Energy Reviews, 69, 188-196. https://doi.org/10.1016/j.rser.2016.11.031

Hasan, R., \& Mekhilef, S. (2017). Highly efficient flyback microinverter for grid-connected rooftop PV system. Solar Energy, 146, 511-522. https://doi.org/10.1016/j.solener.2017.03.015 
Hazama, H., Masuoka, Y., Suzumura, A., Matsubara, M., Tajima, S., \& Asahi, R. (2018). Cylindrical thermoelectric generator with water heating system for high solar energy conversion efficiency. Applied Energy, 226, 381-388. https://doi.org/10.1016/j.apenergy.2018.06.015

Jakhar, S., Soni, M., \& Gakkhar, N. (2017). An integrated photovoltaic thermal solar (IPVTS) system with earth water heat exchanger cooling: Energy and exergy analysis. Solar Energy, 157, 81-93. https://doi.org/10.1016/j.solener.2017.08.008

Kabir, E., Kumar, P., Kumar, S., Adelodun, A., \& Kim, K. (2018). Solar energy: Potential and future prospects. Renewable And Sustainable Energy Reviews, 82, 894-900. https://doi.org/10.1016/j.rser.2017.09.094

Karimi Estahbanati, M., Feilizadeh, M., Jafarpur, K., Feilizadeh, M., \& Rahimpour, M. (2015). Experimental investigation of a multi-effect active solar still: The effect of the number of stages. Applied Energy, 137, 46-55. https://doi.org/10.1016/j.apenergy.2014.09.082

Kalogirou, S. (2009). Solar energy engineering: Processes and Systems. Elsevier/Academic Press.

Khoo, Y., Nobre, A., Malhotra, R., Yang, D., Ruther, R., Reindl, T., \& Aberle, A. (2014). Optimal Orientation and Tilt Angle for Maximizing in-Plane Solar Irradiation for PV Applications in Singapore. IEEE Journal of Photovoltaics, 4(2), 647-653. https://doi.org/10.1109/jphotov.2013.2292743

Li, W., Jin, J., Wang, H., Wei, X., Ling, Y., \& Hao, Y. et al. (2018). Full-spectrum solar energy utilization integrating spectral splitting, photovoltaics and methane reforming. Energy Conversion and Management, 173, 602-612. https://doi.org/10.1016/j.enconman.2018.06.012

Lutgens, F., Tarbuck, E., \& Tasa, D. (2015). The atmosphere: An Introduction to Meteorology. Pearson Education.

Meneguzzo, F., Ciriminna, R., Albanese, L., \& Pagliaro, M. (2015). The great solar boom: a global perspective into the far-reaching impact of an unexpected energy revolution. Energy Science \& Engineering, 3(6), 499-509. https://doi.org/10.1002/ese3.98

Modi, A., Bühler, F., Andreasen, J., \& Haglind, F. (2017). A review of solar energy-based heat and power generation systems. Renewable And Sustainable Energy Reviews, 67, 1047-1064. https://doi.org/10.1016/j.rser.2016.09.075

Nahar, A., Hasanuzzaman, M., \& Rahim, N. (2017). Numerical and experimental investigation on the performance of a photovoltaic thermal collector with parallel plate flow channel under different operating conditions in Malaysia. Solar Energy, 144, 517-528. https://doi.org/10.1016/j.solener.2017.01.041

Oh, J., \& TamizhMani, G. (2010). Temperature testing and analysis of PV modules PER ANSI/UL 1703 and IEC 61730 standards. 201035 Th IEEE Photovoltaic Specialists Conference. https://doi.org/10.1109/pvsc.2010.5614569

Pathak, M., Sanders, P., \& Pearce, J. (2014). Optimizing limited solar roof access by exergy analysis of solar thermal, photovoltaic, and hybrid photovoltaic thermal systems. Applied Energy, 120, 115-124. https://doi.org/10.1016/j.apenergy.2014.01.041

Polman, A., Knight, M., Garnett, E., Ehrler, B., \& Sinke, W. (2016). Photovoltaic materials: Present efficiencies and future challenges. Science, 352(6283), aad4424-aad4424. https://doi.org/10.1126/science.aad4424

Quansah, D., Adaramola, M., Appiah, G., \& Edwin, I. (2017). Performance analysis of different grid-connected solar photovoltaic (PV) system technologies with combined capacity of $20 \mathrm{~kW}$ located in humid tropical climate. International Journal Of Hydrogen Energy, 42(7), 4626-4635. https://doi.org/10.1016/j.ijhydene.2016.10.119

Quaschning, V. (2005). Understanding renewable energy systems. Earthscan.

Sahota, L., \& Tiwari, G. (2017). Review on series connected photovoltaic thermal (PVT) systems: Analytical and experimental studies. Solar Energy, 150, 96127. https://doi.org/10.1016/j.solener.2017.04.023

Sandnes, B., \& Rekstad, J. (2002). A photovoltaic/thermal (PV/T) collector with a polymer absorber plate. Experimental study and analytical model. Solar Energy, 72(1), 63-73. https://doi.org/10.1016/s0038-092x(01)00091-3

Sardarabadi, M., Passandideh-Fard, M., \& Zeinali Heris, S. (2014). Experimental investigation of the effects of silica/water nanofluid on PV/T (photovoltaic thermal units). Energy, 66, 264-272. https://doi.org/10.1016/j.energy.2014.01.102

Shyam, Tiwari, G., Fischer, O., Mishra, R., \& Al-Helal, I. (2016). Performance evaluation of N-photovoltaic thermal (PVT) water collectors partially covered by photovoltaic module connected in series: An experimental study. Solar Energy, 134, 302-313. https://doi.org/10.1016/j.solener.2016.05.013

Silva, D. V. e., Silva, J. R. B. da., Oliveira, S. R. de., Andrade, R. O. de., Figueiredo, C. F. V. de., Sousa, G. de M., Costa, M. M. L. da., Formiga, A. C. de S., Oliveira, F. F. D. de., Oliveira, P. A. T. de., Nascimento, R. R. A., \& Medeiros, R. L. B. de. (2020). Estudo da viabilidade econômica de uma usina fotovoltaica em uma instituição de educação superior no semiárido paraibano. Research, Society and Development, 9(11), e4879119886. https://doi.org/10.33448/rsdv9i11.9886

Silva, S. T., \& Sousa, N. G. (2020). Uso da energia solar como fonte alternativa para o aquecimento de utilidades: simulação e controle. Research, Society and Development, 9(3), e188932730. https://doi.org/10.33448/rsd-v9i3.2730

Singh, D., Yadav, J., Dwivedi, V., Kumar, S., Tiwari, G., \& Al-Helal, I. (2016). Experimental studies of active solar still integrated with two hybrid PVT collectors. Solar Energy, 130, 207-223. https://doi.org/10.1016/j.solener.2016.02.024

Solarex (1999). MSX-77 and MSX-83 Photovoltaic Modules.

Sreeraj, E., Chatterjee, K., \& Bandyopadhyay, S. (2013). One-Cycle-Controlled Single-Stage Single-Phase Voltage-Sensorless Grid-Connected PV System. IEEE Transactions on Industrial Electronics, 60(3), 1216-1224. https://doi.org/10.1109/tie.2012.2191755

Tripathi, R., \& Tiwari, G. (2017). Annual performance evaluation (energy and exergy) of fully covered concentrated photovoltaic thermal (PVT) water collector: An experimental validation. Solar Energy, 146, 180-190. https://doi.org/10.1016/j.solener.2017.02.041 
Research, Society and Development, v. 10, n. 7, e1210716156, 2021

(CC BY 4.0) | ISSN 2525-3409 | DOI: http://dx.doi.org/10.33448/rsd-v10i7.16156

Tripathy, M., Yadav, S., Panda, S., \& Sadhu, P. (2017). Performance of building integrated photovoltaic thermal systems for the panels installed at optimum tilt angle. Renewable Energy, 113, 1056-1069. https://doi.org/10.1016/j.renene.2017.06.052

van Helden, W., van Zolingen, R., \& Zondag, H. (2004). PV thermal systems: PV panels supplying renewable electricity and heat. Progress In Photovoltaics: Research and Applications, 12(6), 415-426. https://doi.org/10.1002/pip.559

von Roedern, B., \& Ullal, H. (2008). "The role of polycrystalline thin-film PV technologies in competitive PV module markets". 2008 33Rd IEEE Photovolatic Specialists Conference. https://doi.org/10.1109/pvsc.2008.4922493

Yandri, E. (2017). The effect of Joule heating to thermal performance of hybrid PVT collector during electricity generation. Renewable Energy, 111, 344-352. https://doi.org/10.1016/j.renene.2017.03.094 